\title{
Chapter 4 \\ Eifel-Rur: Old Water Rights and Fixed Frameworks for Action
}

\author{
Rodrigo Vidaurre, Ulf Stein, Alison Browne, Maia Lordkipanidze, \\ Carina Furusho, Antje Goedeking, Herbert Polczyk \\ and Christof Homann
}

\subsection{Introduction}

This chapter summarises our analysis of drought governance in the Eifel-Rur region of Germany. Within the Interreg IV-B project DROP a team of researchers from five universities and knowledge institutes performed two field visits to the Eifel-Rur region and held interviews with authorities and stakeholders. The visits were facilitated by the DROP project partner Eifel-Rur Waterboard (Wasserverband Eifel-Rur, WVER). Interviews were both individual and in group settings; in the second visit interim results were presented to stakeholders in a workshop. Stakeholders interviewed included representatives from drinking water producers, nature protection authorities, industrial water users, farmer representatives, electricity generating companies, environmental NGOs, fishermen, sailing schools, and local (municipal) and regional (district) authorities in charge of water management. The analysis was guided by a drought-specific Governance Assessment Tool (GAT), which uses five governance dimensions (levels and scales, actors and networks, problem perceptions and goal ambitions, strategies and instruments, responsibilities and resources) and four governance criteria (extent, coherence, flexibility and intensity) in its analysis.

R. Vidaurre $(\bowtie) \cdot$ U. Stein

Ecologic Institute, Pfalzburger Strasse 43/44, 10717 Berlin, Germany

e-mail: rodrigo.vidaurre@ecologic.eu
A. Browne
University of Manchester, Manchester M13 9PL, UK
M. Lordkipanidze
University of Twente, PO Box 7658, 8903 JR Leeuwarden, The Netherlands
C. Furusho
IRSTEA, Antony, France
A. Goedeking $\cdot$ H. Polczyk $\cdot$ C. Homann
Eifel-Rur Waterboard-WVER, Düren, Germany
(C) The Author(s) 2016
H. Bressers et al. (eds.), Governance for Drought Resilience,
DOI 10.1007/978-3-319-29671-5_4 
In the following, we present the context of water management in the Eifel-Rur region, describe some drought actions which have already been implemented, explain the results of our analysis in terms of the Governance Assessment Toolkit and present our recommendations for improved drought governance in the region.

An aspect of the Eifel-Rur water management system which is central for its drought governance is the water rights' system in place. The region's water rightssome of them centuries old - provide their owners with very strong legal claims to the resource; furthermore, the current system of rights and charges does not provide real incentives for users to reduce their water rights/water use. These features make the demand side of the water system very inflexible. In addition, the region's significant number of reservoirs allows for a very stable supply of water over time, which means that users are not prone to include risks related to water supply into their risk strategies. This lack of flexibility poses significant challenges for drought management, some of which are taken up in the final section "Conclusions and Case-Specific Recommendations".

\subsection{The Who, What and When of Drought Governance in the Eifel-Rur Region}

\subsubsection{Water Management in North Rhine-Westphalia}

In Germany, the EU's Water Framework Directive (WFD) was transposed into national law via the seventh amendment to the Federal Water Act (Wasserhaushaltsgesetz, WHG) in June 2002. ${ }^{1}$ Due to a major restructuring of responsibilities and competencies between the Federal Government and the German Länder in 2006, the German water legislation was modified in 2009; the modified Federal Water Act entered into force in 2010.

According to this act, in their implementation of the WFD the German federal states must adopt their state water laws to encompass water protection and to formulate the roles for cities, municipalities and water authorities, who bear the concrete responsibility for implementing measures. In the case of North Rhine-Westphalia, the responsibility for developing the river basin management plans lies with the Highest Level Water Authority which is the North Rhine-Westphalian Ministry for Environment and Nature Protection, Agriculture and Consumer Protection. Plans are adopted in consultation with the High Water Level Authorities (District Councils) and the responsible committee of the North Rhine-Westphalia regional parliament (Landtag). Responsibility for implementation lies with lower level public administration, such as districts and cities. Further actors such as nature protection organisations, water associations and regional councils should participate in the planning and particularly in the implementation process. Regarding water abstractions, it is the

\footnotetext{
${ }^{1}$ Grüne Liga (n.d.): Umsetzung der Richtlinie in deutsches Recht. http://www.wrrl-info.de/docs/ tafel7_a3.pdf.
} 
District Councils who are responsible for authorisation of water abstraction for surface water and groundwater.

In the particular case of the Eifel-Rur river basin, the district government in Cologne (Aachen) is responsible for implementation of the WFD on the ground. The measures are financed $80 \%$ from the state government and $20 \%$ from own contribution (e.g. the municipalities where they are responsible).

North Rhine-Westphalia's water management is quite particular in the German context, as it relies on waterboards to perform many of the duties of water management. This particular form of organising water management has its origins in the nineteenth century, in response to the large-scale water-related challenges of North Rhine-Westphalian coal mining. The responsibilities of the waterboards are established in a particular law for each single waterboard. The next section describes the responsibilities of the WVER.

\subsubsection{The Eifel-Rur Waterboard (WVER)}

WVER is a public water corporation in the district of Cologne (one of the five governmental districts of North Rhine-Westphalia), similar in nature to a water authority. It is a public body which is an operating organisation, executing different tasks set by the special North Rhine-Westphalian law Gesetz über den Wasserverband Eifel-Rur ("Law on the Water Association Eifel-Rur"). An important point is that the WVER is limited to executing powers, without any rights of an authority (e.g. it cannot issue permits). The WVER region comprises mainly the catchment of the Rur and has approx. $2.087 \mathrm{~km}^{2}$ and ca. 1.1 million inhabitants.

WVER responsibilities comprise the full range of water services. Duties of WVER by law include control of water discharge in catchment area, river maintenance, river restoration, supply of raw water for drinking water production, supply of production water, wastewater treatment, prevention of disadvantageous influences on river systems (in general looking at different issues) and hydrology. Groundwater is not included under WVER's duties, as only the northern low-lying part of WVER's area has significant groundwater bodies. In this region open-cast coal mines are situated which influence the groundwater table, but even larger mines are situated in the adjacent catchment area, which also influence the groundwater table in the northern Rur region. As a consequence, groundwater management has been entrusted to the waterboard in this neighbouring catchment.

In addition to its legal obligations, WVER informally collaborates with further actors to achieve additional objectives including keeping reservoir levels high enough for water quality, sailing and to ensure a pleasant landscape (tourism); managing reservoir levels in a way that minimises disturbances of fish reproduction, and electricity production by the company RWE.

WVER operates six reservoirs with a total capacity of 300 million cubic metres in the northern part of the Eifel hills, which corresponds to the southern part of its service area. The reservoirs were mainly developed for flood control and flow 
maintenance during dry seasons. Stillwater in these reservoirs always bears the risk of eutrophication with effects such as algal blooms, etc. Concerning climate change, with longer dry and sunny periods, this problem is expected to increase.

The total length of flowing surface waters in the WVER service area managed by the waterboard is approx. $1900 \mathrm{~km}$. (These are all the waters in the northern part of the service area downstream of the reservoirs.) WVER is responsible for the management of these waters, as well as for the operation of 50 flood retention basins and other flood control works.

\subsubsection{The Role of Municipalities and Lower Water Authorities in Water Management}

The German Basic Law (Article 28 (2)) and most constitutions of the German Länder ensure the local self-government of districts, towns and municipalities. Self-government comprises all matters concerning the local community. Municipal regulations and the water laws of the different German federal states stipulate that drinking water supply is usually, and wastewater disposal is always, an obligation of the local authorities. On that basis, municipalities decide on the local implementation and organisation of water supply and wastewater disposal.

With a view to effectively realising drinking water supply and wastewater disposal, municipalities may form associations for voluntary cooperation. To some extent, municipalities (such as in North Rhine-Westphalia) are members of water management associations (Wasserverbände, such as the Waterboard Eifel-Rur), which are subject to special laws. ${ }^{2}$ In addition to these compulsory tasks, municipalities have to fulfil partial tasks regarding the implementation of environmental laws issued by the government and the German Federal States.

Among other responsibilities, the lower water authorities, as supervisory/ executive authorities, approve flooding areas, wastewater systems, wastewater treatment plants, small sewage works, wastewater and rainwater discharges, water supply facilities, the use of water bodies, such as abstraction from surface water and exceptional approvals for water and medicinal spring protection areas.

\subsubsection{Historical Approach to Droughts and Their Effects on Drinking Water and Water Quality}

There is as yet no strategic, long-term approach to drought management in North Rhine-Westphalia's water management. There is also no incorporation of climate

\footnotetext{
${ }^{2}$ Profile of the German Water Sector (2011), available under http://www.dvgw.de/fileadmin/dvgw/ wasser/organisation/branchenbild2011_en.pdf.
} 
change and its impacts on water availability in the planning tools and instruments used in water management of the Waterboard Eifel-Rur. Water management is based on historical data sets, and no prognoses have been developed to account for altered conditions in the future. At the moment of writing, and excepting the work performed in the DROP pilot (see next section), only a first prognosis on water quantity in the Rur system within different climate change scenarios has been developed (within the AMICE project, a further INTERREG IV-B project). A prognosis on water quality is to the moment also lacking. ${ }^{3}$

North Rhine-Westphalia has as yet not much experience with drought episodes; it has a comparatively humid climate due to its proximity to the Atlantic. In the case of the Waterboard Eifel-Rur, the few droughts in the past have been dealt with on an ad hoc basis: water management measures have been developed that alleviate a particular impact over a short period of time. The requirement for action has arisen not due to considerations related to droughts themselves (e.g. anticipatory management in early stages of drought to prepare for possible worsening), but due to other requirements, such as upholding water quality commitments.

\subsection{Measures Taken: Addressing Drought in the Eifel}

In the upper catchment of the Rur, six reservoirs were built in the Eifel hills mainly to control the effects of flooding and to maintain the flow during dry seasons. Five of them form an interconnected system around the main reservoir 'Rurtalsperre'. The most upstream dam is placed in the tributary Olef and called 'Oleftalsperre'. It is a multifunction reservoir with a storage capacity of 19 mio. m3. The 'Oleftalsperre' was built for the protection against floods, for low-water enrichment and for the provision of raw water for tap-water production. The Olef mouths info the next tributary the Urft. There the 'Urfttalsperre' is situated. It is the oldest dam in the northern Eifel with a storage capacity of 45 mio. $\mathrm{m} 3$. The outflow of the dam flows in very dry periods directly into the next basin 'Obersee', a preimpoundment basin of the 'Rurtalsperre'. This next basin serves among other things also as a reservoir providing the agency in charge with water for production of drinking water. The 'Obersee' flows into the biggest reservoir the 'Rurtalsperre' (202 mio. m3). This is also a multifunction reservoir without direct storage for tap-water production, but among other things a lot of tourism, which is based on a large lake with good water quality.

These reservoirs were often shaped as filled constructions with a stream/river flowing through the basin as a stream. Big reservoirs in the catchment area of the Rur such as the dams in the northern Eifel cannot be disconnected from the river, because their retention volume cannot be replaced by a near-natural reconstruction of the river course. With a total capacity of 300 mio. $\mathrm{m} 3$ their function for flood

\footnotetext{
${ }^{3}$ Antje Goedeking, WVER, personal communication.
} 
control is very important. Consequently, an adaptation to climate change is only possible by an adaptation of the management of the dams.

In addition to flood protection, the 'Rurtalsperre' reservoir system serves additional important aims. Among the reservoir system's functions is that of providing good quality raw water for drinking water production. Whereas the different aims do not always go in line with each other, still all of them have to be served. For example, sometimes a controlled high discharge out of the reservoir is needed in order to prevent flooding, but this can only be carried out to such an extent that there is still enough water in the reservoirs to produce drinking water and maintain the flow in dry periods.

Recently, Eifel-Rur region has experienced somewhat dryer periods during the spring season, as a result of which the water flow through the reservoirs decreases. Stillwater and falling water levels in reservoirs bear the risk of a decrease in water quality, which results in a higher amount of production work and possibly drinking water production problems; stillwater in these reservoirs always bears the risk of eutrophication with effects such as algal blooms. Due to the topography and the limited capacity, the 'Oleftalsperre' and the 'Urfttalsperre' run the risk of more algal blooms during long dry periods. This can also have consequences on the reservoirs 'Obersee' and 'Rurtalsperre' downstream.

Concerning climate change with longer dry and sunny periods this problem is expected to increase. At present there is a lack of knowledge about the behaviour of the water quality within the dry scenario. The long dry periods in spring in the last years already resulted in a loss of water quality in some of the reservoirs.

The following map presents the main surface water reservoirs' location (Fig. 4.1).

The Waterboard Eifel-Rur has executed a project to improve water reservoir management. The project aims to prevent deterioration of the water quality in the reservoir system. To this purpose the waterboard analysed the inflow patterns in the different dams. Based on these results, a study was carried out on the management system of the dams with respect to water quantity and quality. Suggestions for the adaptation of the management plan emerged: one of the best results obtained is to add a drought index in the management plan, which will help prevent the release of too much discharge in an earlier stage compared to today's practice. This leads to a credit of water in dry periods.

The project thus managed to flexibilise operational decisions to improve the performance of the management system, in which the different obligations of the system are now still met under a wider array of meteorological and flow conditions. Whereas certain dry conditions in the past would have made it impossible to meet all obligations, under the improved system this would now be possible. However, the issue of flexibilising the obligations is in our opinion not yet satisfactorily addressed. Particularly, the water rights regime ensures constant supply to water users, and contains no incentives to reduce these water rights where there could be potential for such reductions. The following sections present this situation in more detail. 


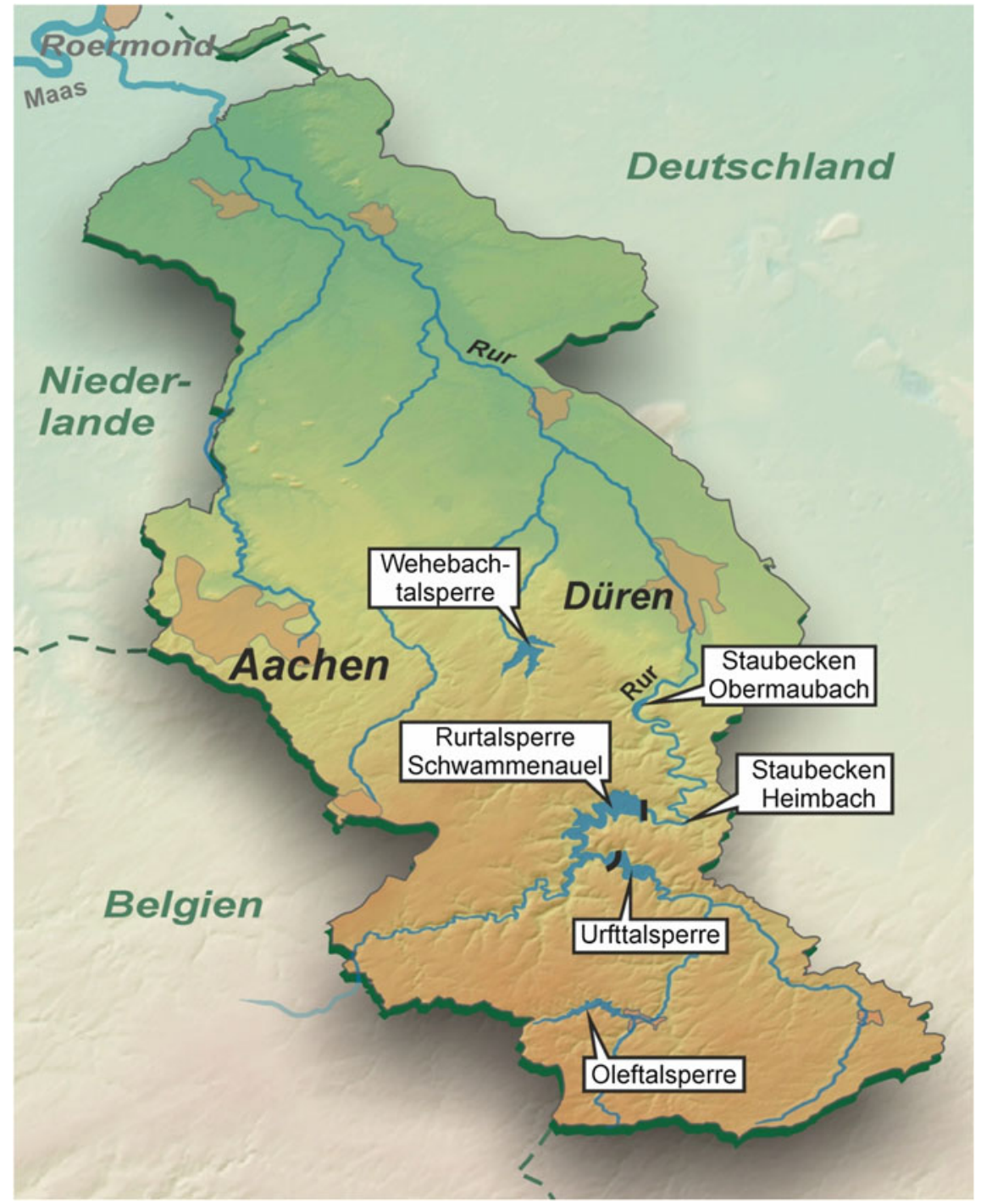

Fig. 4.1 WVER region in the catchment of the Rur River, including the the main reservoirs in the Eifel region

\subsection{Governance Assessment: From High Coherence to Low Flexibility}

In the following section an analysis of drought governance in the Eifel-Rur region is presented. It is structured along the four qualities of the GAT. 


\subsubsection{Extent}

The extent aspects of the governance context can mostly be regarded as somewhat positive, covering all levels and scales of the system. Many administrative levels are directly involved in the water management system. The two main actors are the district government (second authority level) and the waterboard itself. When it comes to droughts, the national level (German Ministry of Environment) is still somewhat decoupled, mainly providing first studies and visions. The EU level is quite relevant for its directives. However, a negative point is that municipalities are seen to be withdrawing from their water management responsibilities, mainly due to serious resource issues.

When focussing on the actors, the same positive extent can be appreciated. This is a result of the design of the North Rhine-Westphalian waterboards: according to the law regulating WVER, users with a water right of a certain size are automatically members of the waterboard, whether they like it or not. This means that all major users participate - also economically — in the management of the water basin. There are, however, some restrictions to this positive extent regarding actor involvement. Smaller (and thus non-paying) actors, such as farmers and nature organisations, do not have the same voice as larger actors. This been said, there is a strong movement towards collaborative and inclusive decision-making processes on the side of the water authorities, as well as on relationship building on the side of WVER. The implementation of the WFD and the Floods Directive for instance were based on a huge number of participatory workshops and roundtable discussions, and there is a strong emphasis on voluntary implementation of measures. Interviewed stakeholders repeatedly mentioned that the developments over the last decades had been very positive in this sense.

The implementation of WFD and Floods Directive has provided the region with a set of new instruments and experience in consultation processes with stakeholders, and all in all, there is a broad extent of strategies and instruments in place. However, from a drought perspective there are very significant elements still missing, e.g. water demand management, drought contingency planning, communication, etc. In this context there is still room for improvement, e.g. via knowledge transfer of experiences from other pilot regions. Another point affecting drought management in particular is the fact that the district government does not currently see itself in a position to actively push the topic of droughts - whereas they welcome the waterboard's actions on the topic, they are currently suffering due to overstretched resources. This means that those actors could implement measures on the ground if they were required to face no external pressure to act on the topic. 


\subsubsection{Coherence}

Passing to the governance system's coherence, the evaluation is also quite positive. The main actors, such as the state level, the districts, the municipalities, the water authorities and the drinking water companies, mutually accept their share of the tasks, responsibilities and funding given by law. The dependence among these levels is well recognised by the interviewed individuals. EU environmental policies seem to have played an important role in introducing a more holistic and synergistic approach to the management of the reservoirs. To some degree the coordination of the lower competent authorities appears to be more coherent than that at a higher level.

Among the factors determining a positive degree of coherence is that the WVER is in charge of practically all relevant water management tasks in the region. All these responsibilities being within one organisation rather than distributed between different actors is probably helpful in establishing a coherent framework. The institutional structure of WVER also helps that with water users also being the waterboard members, involved in decision-making and paying for the services provided, this structure provides a framework conducive to good coherence of, for example, perceptions, goal ambitions, strategies and instruments. In addition, different stakeholders have goals that match quite well. For instance, the fishermen associations are interested in large fish populations in the reservoirs, which are also of interest to the waterboard in their role of drinking water supplier because of fish population's positive effects on water quality, in their role of responsible for WFD implementation, and also for the objectives of the national park authorities.

In the WVER region, the interviews show a sense of trust and mutual dependency between the actors, expressed for instance in their positive evaluation of participatory approaches being used in water management. All actors interviewed were quite satisfied by the way the waterboard is working with them and how actors' perspectives are considered when proposing measures, for instance, for the implementation of the WFD. All in all, the stakeholders interviewed expressed their belief in the extremely high value of the trust-based collaboration that has been built over the years, and that has evolved positively over time. However, the consensual and voluntary approach towards measure implementation seems in some cases to be reaching its limits, with some negotiation processes on contentious topics being practically at a standstill for a number of years now.

This notwithstanding, we can identify potential conflicts of interest that could worsen in case of water scarcity. The existence of very old water rights (with strong legal precedence) seems to create opposing goals between some users from a drought perspective. Industry users with a certain water right do not at present have incentives to reduce their water use or to partly reduce their water rights. A further point is that the strategy for flood prevention implies keeping the water level in the reservoir sufficiently low until the spring, to ensure enough storage capacity in case of exceptional precipitation events which may be associated with intense rainfall or snow melt. However, if there is not enough precipitation or snow melt during the 
spring period when water is collected, there is not enough water meeting the quality conditions for some drinking water providers (e.g. water temperature below $10^{\circ} \mathrm{C}$ and oxygen above $4 \mathrm{mg} / \mathrm{l})$. Furthermore, there is a lack of coherence when it comes to resources; in particular, there are a lot of issues with municipalities being extremely cash-strapped at the moment as well as in the foreseeable future.

This said, it is also true that drought can be considered a second-order problem and the extent to which conflicts related to drought and water scarcity have emerged is really quite limited - with the exception of punctual issues of water supply and water quality between core actors WVER and a water supply company.

\subsubsection{Flexibility}

The overall evaluation of the governance system's flexibility is only intermediate with, however, some positive developments over time. This evaluation is based on the fact that the water management system has a quite rigid large-scale framework, shown fundamentally in the priorities and responsibilities of WVER (established by law) and its operational procedures. The management of the water system in the Eifel valley follows a clearly established set of complex management rules which WVER helps elaborate and which are authorised by the district authority of Cologne. Any management decision that disregards these rules can bring with it the question of legal responsibility - for instance for flood damages ensuing due to incorrect flood protection. This means that WVER and its personnel have a strong incentive not to stray from this set of rules.

The framework is both difficult and slow to change, and some actors see it as problematic for the system to take on-board new responsibilities. However, the water management system shows very significant flexibility at the small scale, within the rooms provided by this overall fixed framework. There is a strong culture of discussion and collaboration between actors, and interviewed stakeholders were broadly of the opinion that their interests are considered and taken on board as much as possible.

The legal obligation of the waterboard to provide a certain established level of protection (floods) and of supply (deliver water for drinking water production) and the responsibilities associated with it have resulted in an elaborate and sophisticated set of rules that manage the interaction of reservoirs and water bodies. However, these same legal obligations imply that there is no short-term possibility of officially incorporating additional risks (e.g. droughts) into the set of principles which govern the system. Even smaller changes have to be extremely well-founded and well-argued, based on thorough evidence and modelling of historic data, which means that the overall framework is destined to be rather more reactive than proactive, and that these reactions will tend to take time. The management of secondary objectives or of other unconsidered aspects can only be improved if it can be shown that primary objectives are not affected. This means that the 
adaptation of dam management rules (e.g. so that they incorporate drought considerations) is a lengthy procedure.

This said, there is significant capacity, responsibilities and resources to address different issues in a way that does not interfere with the overall framework; there is also the will among actors to address new risks and topics. The district authorities and WVER's approach to the implementation of European directives foresees amicable agreements/cooperation with affected parties, showing high degree of flexibility in on-the-ground implementation. It seems possible to reassign responsibilities in the definition of water resource problems related to flooding, and possibly nature. Resources, however, seem a different issue altogether, with the system quite fixed. The question of available resources seems very important in the final implementation, particularly where municipalities are involved.

Flexibility is also shown in the way that topics pushed by stakeholders have been taken up by the relevant authorities. The question of enabling the return of salmon to the region's rivers was initially pushed by fishermen, who managed to convince authorities to take up these objectives. Regarding implementation and crisis situations, there does not seem to be much flexibility in moving up and down levels, as main decisions are mostly taken by the highest authorities in realising certain plans. Depending on the issue at stake, the decision is often brought up automatically to the superior levels, e.g. the district government.

The ability to include new actors into formal structures of responsibility seems questionable as the structures within WVER and its 'assembly' seem fixed. However, informal relationships are seen to be a way forward in this regard, with new actors being addressed in participation processes, and adjustments to the distributions of responsibility seeming possible.

\subsubsection{Intensity}

Currently, the relatively weakest point of the governance context for drought resilience policies and measures is its intensity. (However, this also holds true in other DROP pilot regions in Northwest Europe, due to the region being overall quite water-abundant.)

The district government seems to constitute the most relevant level in the decision chain concerning water issues related to drought. (It should be remembered that the waterboard only has executing powers, and thus cannot implement on its own accord measures for a new issue such as drought.) At the national and at the Länder level, initiatives addressing climate change adaptation have been launched, but are as yet only limited to knowledge exchange and studies. Improving drought resilience has no priority on the political agenda (or not yet at least) and no resources are made available for this topic. According to the district government, the German and North Rhine-Westphalian Adaptation Strategies do not have 
implications for their daily work, because they are too unspecific to result in concrete requirements and actions. As a consequence, there seems to be a lack of plans or other instruments regarding drought adaptation, as well as a lack of long-term vision for this issue.

This means that the district government is under no pressure due to obligations on the topic of climate change adaptation in general or drought in particular, and nor have the relevant resources been made available. Although they recognise the importance of the issue, they do not see themselves in a position to take it up, and so the district government is currently not driving any process (e.g. establishing its own guidelines, programmes, or implementing adaptation initiatives). It is individual actors that are initiating interesting activities - the DROP project being one of them. The Waterboard Eifel-Rur, a drinking water producer and a hydroelectricity producer interviewed all emphasised the existence of technical projects to enhance the system's robustness, improve risk management and develop backup solutions in case of extreme events. We can say that drought prevention is being addressed in the context of general risk management strategies that use as inputs' precipitation patterns.

WVER can thus be described as the driving force of change in the region. As the responsible for most things water in the Eifel, they are also the first in line to be affected by drought issues, which explains their taking a proactive approach. The overall assessment of the intensity is thus low, but with increasing strength.

\subsection{Improving Drought Governance in the Eifel: Conclusions and Recommendations}

\subsubsection{Conclusions}

The observations mentioned in the above section let us conclude that the governance context for drought resilience in the Eifel-Rur can be regarded at the moment as "intermediate". Figure 4.2 shows that the system is overall coherent and shows a fair extent in most governance dimensions, but there is plenty of room for improvements in terms of flexibility and intensity.

This evaluation of the drought governance system as "intermediate" is the result of a general framework which is quite positive for overall water management, but which from a perspective specific to droughts includes interactions which detract from this positive evaluation. We would like to highlight two main ones in this concluding section. First, the system of water rights and the associated water user charges is unduly inflexible, in which it does not allow for creating incentives to reduce water rights. The water rights' system provides strong guarantees for users - in line with a water provision which can offer high security of supply due to its system of reservoirs - but this rigidity has the potential to become problematic both under drought conditions and when faced with longer term impacts of climate 


\begin{tabular}{|c|c|c|c|c|}
\hline & \multicolumn{4}{|c|}{ Governance Criteria } \\
\hline $\begin{array}{l}\text { Governance } \\
\text { Dimensions }\end{array}$ & Extent & Coherence & Flexibility & Intensity \\
\hline Levels \& scales & & & & \\
\hline Actors \& networks & & & & \\
\hline $\begin{array}{l}\text { Problem } \\
\text { perceptions \& Goal } \\
\text { ambitions }\end{array}$ & & & & \\
\hline $\begin{array}{l}\text { Strategies \& } \\
\text { Instruments }\end{array}$ & & & & \\
\hline $\begin{array}{l}\text { Responsibilities \& } \\
\text { Resources }\end{array}$ & & & & \\
\hline Supportive & & Neutral & & \\
\hline
\end{tabular}

Fig. 4.2 Summary visualisation-Governance context assessment for droughts in the Eifel-Rur region. Arrow up Positive trend in time; Arrow down Negative trend in time

change affecting both water availability and water quality. Second, and related to the first point, is the fact that the waterboard's functions and priorities are established by law. Whereas this has positive impacts in a number of areas, this means that droughts - as well as other emerging and novel issues - can only be addressed within the possibilities provided by the current legal framework. Furthermore, the requirements derived from the legal responsibilities mean that changes (e.g. to operational rules) can only be approved after a lengthy review process. This can significantly increase the time lag between issue identification and measure implementation.

These and other governance issues are also addressed in the following section, in which we present possible recommendations to improve the region's water governance in view of droughts.

\subsubsection{Recommendations}

This section presents possible recommendations to improve, from a drought perspective, the water governance context in the Eifel-Rur region. 


\section{Use current possibilities and develop options to manage water demand}

Although the water system is managed comprehensively and sophisticatedly in the Eifel-Rur, there seems to be a mismatch between the instruments in use for floods, water quality and groundwater, ${ }^{4}$ and those addressing quantitative aspects of surface water management (including those relevant for drought purposes). Whereas the former have profited from recent European regulations that have driven comprehensive updates of planning objectives and tools, the latter is rather the result of the historical development of regional water regulations. For this reason, numerous elements seem to some degree incompatible with each other and with modern water resources management. For instance, there seems to be no real incentive structure in place to manage water demandwhich would have significant overall benefits from a drought perspective. The options we have identified are:

\section{(a) Develop strategy for addressing current inefficiencies}

From a climate adaptation perspective, but also from a broader governance objective of reducing resource use conflicts and thus enhancing planning security for economic actors, a number of possibilities are currently being missed. These inefficiencies could be reduced if a better use is made of existing instruments that could reduce unused water rights to bring them in line with actual use - including realistic development potential for the local industry in the future. Whereas some instruments to this purpose exist, updating historic water rights in the Eifel-Rur may be resisted by affected users, which means that authorities need to count with political will behind their initiative. They would probably also require an improved resource base to address this extra task over several years, as resources already now seem stretched quite thin.

(b) Review water rights and water pricing strategies

New, additional instruments which provide adequate steering mechanisms for managing water demand could also be implemented. For instance, current water charges in the Eifel-Rur region are linked to water use, and not to water rights. Including a link to the size of a water right in the charges, for instance by making charges both water rights and water use (e.g. weighting them in an average), could help address current inefficiencies and missed opportunities.

Interviewees highlighted that owners of water rights would hang on to existing surplus rights for possible future expansion of operations. "Old" rights often provide more legal guarantees than newer ones, which creates unwillingness to trade in old rights for new rights.

\footnotetext{
${ }^{4}$ Strictly speaking, these instruments are not managed by the WVER, as it is not responsible for the relevant groundwater bodies. However, the instruments exist and are implemented by the neighbouring waterboard, which is responsible for the WVERs region's groundwater. For more detailed information cf. Sect. 4.2.2.
} 
(c) Create incentives to explore alternative water supply options

Incentives for increased water efficiency (e.g. water recycling) are not felt everywhere, as water recycling comes at a cost (of energy). There seem to be no initiatives in place exploring alternative water supplies, e.g. rainwater harvesting, significant process water recycling, etc. An impulse to increase process water recycling could be given by making creating an economic case (e.g. making it financially beneficial) for the private companies that are the largest water users in the Eifel-Rur region.

\section{Develop a comprehensive and up-to-date database on water rights and water uses}

Related to the previous point are the significant data issues affecting surface water. Up-to-date information would not always be available, both for the different types of surface water rights, as well as for the different types of actual uses of water. Options such as systematic water metering do not seem to be in discussion. The lack of data would be related to the lack of updated legal requirements mentioned in the previous point.

An adequate management of water resources requires comprehensive and up-to-date data on these points. This is a necessary basis for understanding the system and evaluating the potential for increasing system resilience, e.g. by water demand management. Again, a push for data improvement would probably require both political will and to some extent additional resources. The benefits of increasing the water management system's resilience would in all probability far outweigh the expenditures.

3. Search for synergies between drought preparedness and advisory services/ flood prevention plans

There seems to be a potential for synergies between measures addressing water scarcity and droughts, and other initiatives being implemented in the Eifel-Rur region. For instance, the possibility of including water quantity aspects in the current advisory services to farmers (within the context of the WFD) would seem promising. Interviewees considered examples such as those of the Somerset region (using moisture sensors to address irrigation needs more precisely and thus reduce water use), in which actors have an economic benefit (reduced costs of irrigation) as very viable.

There is also potential to incorporate drought topics and measures into flood prevention planning.

4. Authorities' review of decision-making processes: goalposts and stalled processes

Stakeholders report that some planning processes are somewhat stalled, with little progress over the last $2-3$ years. The deadlock would be a result of trying to achieve consensus and keeping to the traditional voluntary approach in topics which are contentious due to significantly different interests and the high price tags of relatively minor concessions. It would seem that the planning process requires a mechanism for addressing these kinds of impasses. Some stakeholders also wished a clearer guidance on the overall process objectives (the 
"goalposts") from the responsible authorities. In some cases there may be the requirement for authorities to take a somewhat stronger role. There would also seem to be room for a heightened role for authorities in controlling the on-the-ground implementation of its regulations.

5. Develop strategies to maintain in, and add actors to, the planning processes

Strategies could be developed to maintain in, and add actors to, the planning processes. Municipalities in particular seem to be finding it very hard to participate in water management, as many are facing extremely significant resource bottlenecks. Particularly, the financing possibilities of any possible measures addressing drought should be given thorough attention. Other actors can be addressed by demonstrating the benefits of particular initiatives, e.g. by local showcasing of the implementation of certain measures.

\section{Increase synergies with farmers}

Farmers are a stakeholder group of relevance in the downstream area of Eifel-Rur and that seem to be in a position to impose their own agenda to a significant extent. There seems to be a reluctance to collaborate with water management objectives (e.g. when measures do not coincide with agriculture aims). For instance, municipalities with strong farming presence would resist repurposing some areas of land for WFD Programmes of Measures, although the legal basis is clearly against them. It could be relevant to try to evaluate how to make the relationship with farmers more productive when it comes to drought preparedness so as to avoid this kind of deadlocks in drought planning. An option would be to explore the additional synergies between the waterboard and farmers on water quantity (with a special focus on possible bottlenecks during the summer season), water quality, or on unrelated topics.

Open Access This chapter is distributed under the terms of the Creative Commons Attribution-NonCommercial 2.5 License (http://creativecommons.org/licenses/by-nc/2.5/), which permits any noncommercial use, duplication, adaptation, distribution, and reproduction in any medium or format, as long as you give appropriate credit to the original author(s) and the source, a link is provided to the Creative Commons license, and any changes made are indicated.

The images or other third party material in this chapter are included in the work's Creative Commons license, unless indicated otherwise in the credit line; if such material is not included in the work's Creative Commons license and the respective action is not permitted by statutory regulation, users will need to obtain permission from the license holder to duplicate, adapt, or reproduce the material. 